\title{
Adsorption of Hexavalent Chromium from Aqueous Solution Using Chemically Activated Carbon Prepared from Locally Available Waste of Bamboo (Oxytenanthera abyssinica)
}

\author{
Tamirat Dula, Khalid Siraj, and Shimeles Addisu Kitte \\ Department of Chemistry, College of Natural Sciences, Jimma University, P.O. Box 378, Jimma, Ethiopia \\ Correspondence should be addressed to Khalid Siraj; chemdocprof@gmail.com
}

Received 12 December 2013; Accepted 9 January 2014; Published 23 February 2014

Academic Editors: S.-H. Kim, C. Stalikas, and Q. Zhou

Copyright (C) 2014 Tamirat Dula et al. This is an open access article distributed under the Creative Commons Attribution License, which permits unrestricted use, distribution, and reproduction in any medium, provided the original work is properly cited.

\begin{abstract}
This study reports on the adsorption of Hexavalent Chromium from aqueous solutions using activated carbon prepared from bamboo (Oxytenanthera abyssinica) waste by $\mathrm{KOH}$ activation heating in an electrical furnace at $1073 \mathrm{~K}$ for $3 \mathrm{hrs}$. Batch adsorption experiments were also carried out as a function of $\mathrm{pH}$, contact time, initial concentration of the adsorbate, adsorbent dosage, and temperature of the solution. Kinetic studies of the data showed that the adsorption follows the pseudo-second-order kinetic model. Thermodynamic parameters showed that adsorption on the surface of BWAC was feasible, spontaneous in nature, and exothermic between temperatures of 298 and $318 \mathrm{~K}$. The equilibrium data better fitted the Freundlich isotherm model for studying the adsorption behavior of Hexavalent Chromium by BWAC. IR spectrum for loaded and unloaded BWAC was obtained using FT-IR spectrophotometer. Adsorption efficiency and capacity of Hexavalent Chromium were found to be $98.28 \%$ at $\mathrm{pH} 2$ and $59.23 \mathrm{mg} / \mathrm{g}$ at $300 \mathrm{~K}$.
\end{abstract}

\section{Introduction}

Out of the various toxic pollutants chromium and its compounds are considered as the most dangerous inorganic water pollutants. Chromium compounds present in the effluents as a result of electroplating, metal finishing, magnetic tapes, wood preservation, leather tanning, pigments, and chemical manufacturing industries $[1,2]$. They can also present in rocks, soils, plants, and animals. This heavy metal occurs in the environment in two oxidation states: trivalent $\mathrm{Cr}$ (III) and hexavalent $\mathrm{Cr}(\mathrm{VI})$. $\mathrm{Cr}(\mathrm{III})$ is considered as an essential trace nutrient for human, while $\mathrm{Cr}(\mathrm{VI})$, in turn, is highly toxic $[3,4]$. Because of its mutagenic and carcinogenic properties, it includes skin irritation to lung cancer, as well as kidney, liver, and gastric damage [5].

Owing to the different toxicities of $\mathrm{Cr}(\mathrm{VI})$, there is a great interest in the speciation and determination of chromium species in environment. A number of treatment methods for the removal of chromium ions from aqueous solutions have been reported, mainly reduction, ion exchange, electrodialysis, electrochemical precipitation, evaporation, solvent extraction, reverse osmosis, chemical precipitation, and adsorption. Most of these methods suffer from drawbacks such as high operational costs and incomplete removal or the disposal of the residual metal sludge [6].

Adsorption by activated carbon is one of the effective techniques for $\mathrm{Cr}(\mathrm{VI})$ ion removal from wastewater because of the high surface area, highly porous character, and relatively low cost of the adsorbent $[7,8]$. Activated carbon is especially known for the effective removal of organic chemicals, inorganic and heavy metal ion pollutants from wastewater in the laboratory as well as in various industries $[9,10]$. Activated carbon can be synthesized by physical treatment, in which the surface of the carbonaceous material is exposed to a stream of gases at high temperature or chemical one where the carbonaceous material is exposed to 
activation agents such as acids, hydroxides, and zinc chloride at low temperature. The major raw materials for production of activated carbon are wood [11], coal [12], nutshells [13-15], and fruit stones $[16,17]$. The main disadvantage of activated carbon is the weak mechanical properties of its surface and that it is easily burned at high operation temperature [18].

Some low cost activated carbons used for removing of Hexavalent Chromium ions such as groundnut husk [19], agrowaste [20], neem leaves [21], sawdust [22], wheat bran [23], rice bran [24], sago waste [25], green coconut shell [26], hazelnut shell [27], olive stone [28], gingelly oil cake [29], and peanut shell $[30,31]$ have all been reported as useful for preparing adsorbents.

Activated carbons derived bamboo wastes have shown great potential for the removal of organic and inorganic waste from the aqueous solution. In present research we have used bamboo waste to develop activated carbon by chemical activation method using $\mathrm{KOH}$ for the removal of Hexavalent Chromium ion.

\section{Materials and Method}

2.1. Preparation of Bamboo Waste Activated Carbon (BWAC). Bamboo (Oxytenanthera abyssinica) waste was collected from Hosanna furniture manufacturing house, which is $230 \mathrm{Km}$ from Addis Ababa (Ethiopia). The waste was air-dried for one month before use. Then it was cut into pieces approximately $1 \times 1 \mathrm{~cm}^{2}$ in size. It was washed with distilled water and dried at $378 \mathrm{~K}$ for $12 \mathrm{hrs}$. This bamboo precursor was immersed in a potassium hydroxide solution ( $25 \%$ by weight/volume). The mixture was dried in an oven overnight at $378 \mathrm{~K}$. The dried bamboo/KOH mixture then was put on a crucible placed in an electrical furnace (Model Nabertherm (R)) for carbonization. The heating rate of carbonization was $10^{\circ} \mathrm{C} / \mathrm{min}$ and continues until the final temperature of $1078 \mathrm{~K}$ was reached and it was kept at this temperature for $3 \mathrm{hrs}$. The produced activated carbon was then cooled down to room temperature. To remove remaining impurities such as ash, the synthesized BWAC was washed with 5\% aqueous solution of $\mathrm{HCl}$, followed by washing with distilled water several times until the $\mathrm{pH}$ of the washing solution was neutral. Prior to adsorption study $\mathrm{HCl}$-treated activated carbon then was dried at $378 \mathrm{~K}$ for $12 \mathrm{hrs}$ and ground into fine particle of $150 \mu \mathrm{m}$ (sieve size) [32].

2.2. Preparation of Stock Solution. All chemicals used in this study were of analytical reagent grade and were used without further purification. Salt of $\mathrm{K}_{2} \mathrm{Cr}_{2} \mathrm{O}_{7}$ was used for the preparation of the standard solutions for the study. The working solutions with different concentrations of the metal ions were prepared by appropriate dilutions of the stock solution with distilled water before use. The initial $\mathrm{pH}$ of the solution was adjusted accordingly with a $\mathrm{pH}$ meter. Thermostated water bath (Model Grant GLS400, England) was used as the medium for the process. The concentrations before and after adsorption of each metal ion were determined using atomic absorption spectroscopy (AAS) (Model Analytik Jena Nov AA 300).

2.3. Characterization of the Adsorbent. Fourier transform infrared (FT-IR) spectra of dried unloaded BWAC and Hexavalent Chromium loaded BWAC were recorded at 400$4000 \mathrm{~cm}^{-1}$ using Spectrum 65, Perkin Elmer model FTIR spectrophotometer, to determine the surface functional groups. Proximate analysis of total ash content, moisture content, volatile matter, and fixed carbon was also performed.

2.4. Adsorption Study. The adsorption study was carried out by contacting $0.25 \mathrm{~g}$ of the activated carbon with $25 \mathrm{~mL}$ of the metal ion solution under different conditions for a period of time in a boiling tube. The adsorption studies are conducted at $300 \mathrm{~K}$ using thermostated water bath to determine the effect of $\mathrm{pH}$, contact time, and initial metal ion concentration on the adsorption. The residual metal ion was analyzed using atomic absorption spectrophotometer. All experiments were carried out in triplicate, and the concentrations given are average values. The initial metal ion concentration in the test solution and the adsorbent dosage were varied to investigate their effect on the adsorption kinetics. The adsorption studies were carried out at different temperatures. This is used to determine the effect of temperature on the thermodynamic parameters. The amount of adsorption at time $t, q_{t}(\mathrm{mg} / \mathrm{g})$, was calculated using the following relation [33]:

$$
q_{t}=\frac{\left(C_{0}-C_{t}\right) V}{W},
$$

where $C_{t}\left(\mathrm{mgL}^{-1}\right)$ is the liquid phase concentrations of metal ion at any time and $C_{0}\left(\mathrm{mgL}^{-1}\right)$ is the initial concentration of the metal ion in solution. $V$ is the volume of the solution (L) and $W$ is the mass of dry adsorbent $(\mathrm{g})$.

The percentage removal of Hexavalent Chromium solution was calculated by using the following equation:

$$
\text { \%Adsorption }=\frac{\left(C_{0}-C_{e}\right)}{C_{0}} \times 100 \text {, }
$$

where $C_{0}$ and $C_{e}\left(\mathrm{mgL}^{-1}\right)$ are the initial and equilibrium concentrations of Hexavalent Chromium ion in solutions.

\section{Result and Discussion}

3.1. Characterization of the Adsorbent. Activated carbons are widely used as adsorbents due to their high adsorption capacity, high surface area, microporous structure, and a high degree of surface. Some important physicochemical characteristics of BWAC are given in Table 1. Moisture content of the carbon has no effect on its adsorptive power; it dilutes the carbon which is necessary for the use of additional weight of carbon during the treatment process. The BWAC samples were determined using standard test method for moisture in AC [38]. The lower ash content and volatile matter are attributed to lower inorganic content and higher fixed carbon. Higher value of fixed carbon shows that the adsorbent is having more efficiency and stability $[39,40]$. 
TABLE 1: Physiochemical characteristics of BWAC.

\begin{tabular}{lc}
\hline Parameter & Value \\
\hline Moisture content (\%) & 9.56 \\
Volatile matter (\%) & 4.66 \\
Ash content $(\%)$ & 21.66 \\
Fixed carbon $(\%)$ & 73.68 \\
Particle size $(\mu \mathrm{m})$ & 150 \\
$\mathrm{pH}$ & 7.00 \\
\hline
\end{tabular}

FT-IR spectrum is an essential tool to identify the surface functional groups which can contribute significantly to enhance adsorption efficiency of the activated carbon by surface complexation. The spectra show that the activated carbon spectrum was closely identical to bamboo charcoal. A broad peak around $3458 \mathrm{~cm}^{-1}$ was attributed to $\mathrm{O}-\mathrm{H}$ stretching vibration of the hydroxyl group. A peak around $2923 \mathrm{~cm}^{-1}$ was attributed to aliphatic methyl asymmetric $\mathrm{C}-\mathrm{H}$ stretching. The peak observed around $1577 \mathrm{~cm}^{-1}$ was because of $\mathrm{CH}_{2}$ bending. The peak observed around $1457 \mathrm{~cm}^{-1}$ can be attributed to the $\mathrm{CH}_{3}$ bending. The bands around $1196 \mathrm{~cm}^{-1}$ region were alcoholic $\mathrm{C}-\mathrm{O}$ stretching, which produce strong bands. The very weak absorption which was observed at 850 and $603 \mathrm{~cm}^{-1}$ was attributed to the long chain band of aliphatic alkane.

Figure 1 shows the FT-IR spectra of activated carbon before and after adsorption of chromium onto BWAC. It clearly shows that after the adsorption of Hexavalent Chromium on BWAC there is a small shift in frequency values and some of the frequency regions were absent. This observation indicated the participation of adsorption of Hexavalent Chromium on bamboo waste activated carbon (BWAC).

3.2. Effect of $\mathrm{pH}$ on Adsorption. The effect of $\mathrm{pH}$ on the adsorption of the metal ions was carried out within the range that was not influenced by the metal precipitation. The procedure used is similar to those earlier reported [33].

It can be seen in Figure 2 that the maximum of Hexavalent Chromium adsorption (98.28\%) occurs at the lowest $\mathrm{pH}$ value. This finding has been reported by several investigators [41, 42], who have found that Hexavalent Chromium removal by activated carbon is enhanced in the acidic range of $\mathrm{pH}$. The favorable effect of low $\mathrm{pH}$ can be attributed to the neutralization of negative charges on the surface of the adsorption by excess hydrogen ions, thereby facilitating the diffusion of hydrogen chromate ions $\left(\mathrm{HCrO}_{4}{ }^{-}\right)$and their subsequent adsorption. According to Muhammad et al. [43], $\left(\mathrm{HCrO}_{4}^{-}\right)$is the dominant and ionic form of Hexavalent Chromium between $\mathrm{pH} 2.0$ and 4.0. This ionic form was found to be preferentially adsorbed on the surface of carbon. The negative charges could result from oxygenated functional groups of basic character such as lactones or hydroxyl groups, physically adsorbed at the surface of the pores of activated

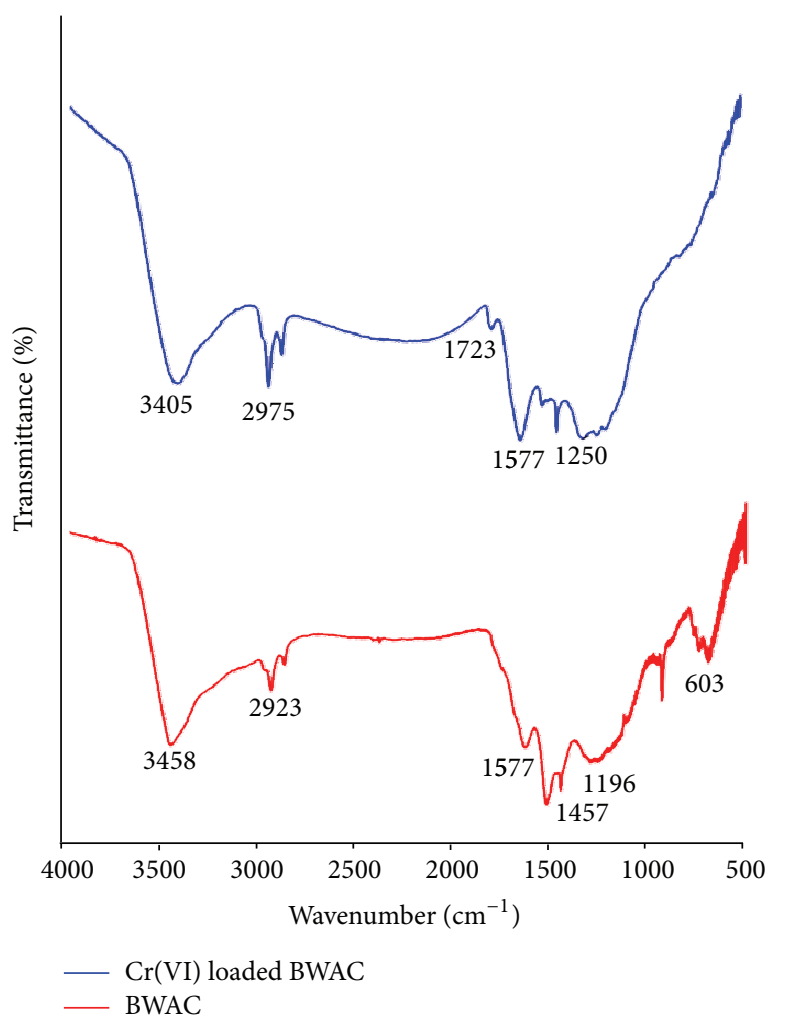

FIGURE 1: FT-IR spectra of BWAC before and after adsorption of Hexavalent Chromium.

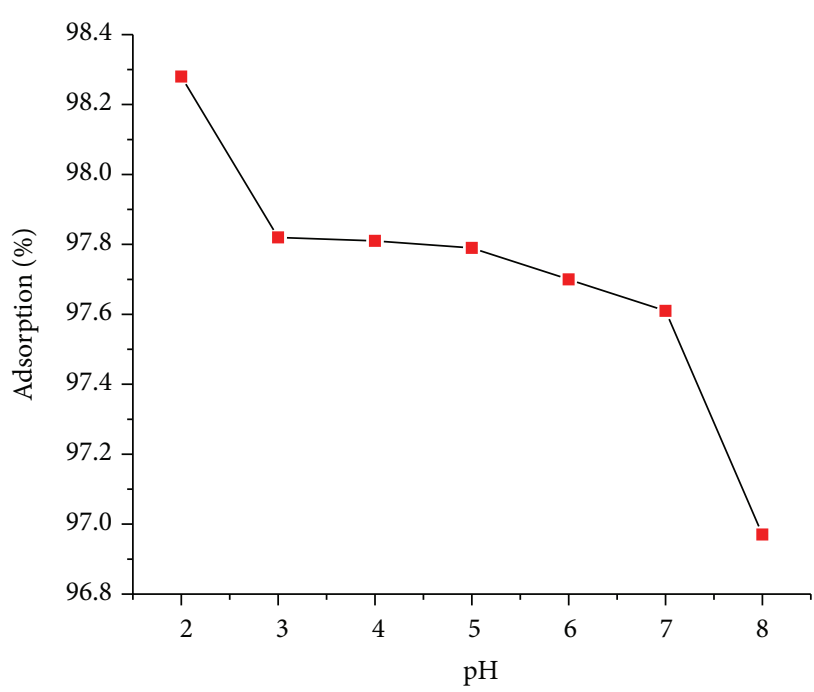

FIgURE 2: Effect of $\mathrm{pH}$ for adsorption of Hexavalent Chromium.

carbon. In view of this observation the optimum $\mathrm{pH}$ for Hexavalent Chromium adsorption is taken to be 2 .

3.3. Effect of Contact Time on Adsorption. The adsorptions of the metal ions by activated carbon were studied at various time intervals (3-120 min) and at a concentration of $100 \mathrm{mg} / \mathrm{L}$. Figure 3 shows that chromium uptake is fast for the first 3-20 min, respectively, and, thereafter, they proceed 


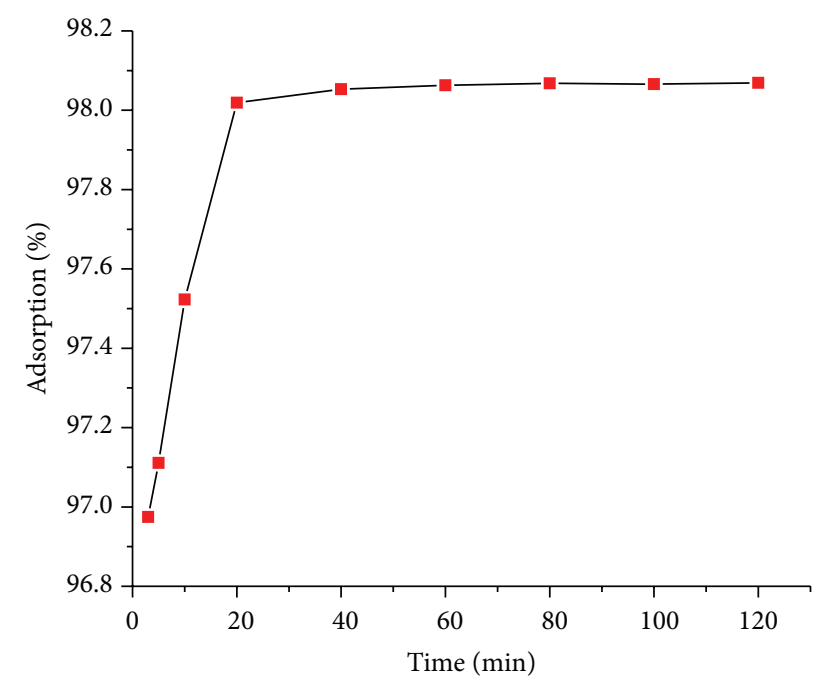

Figure 3: Effect of contact time for adsorption of Hexavalent Chromium.

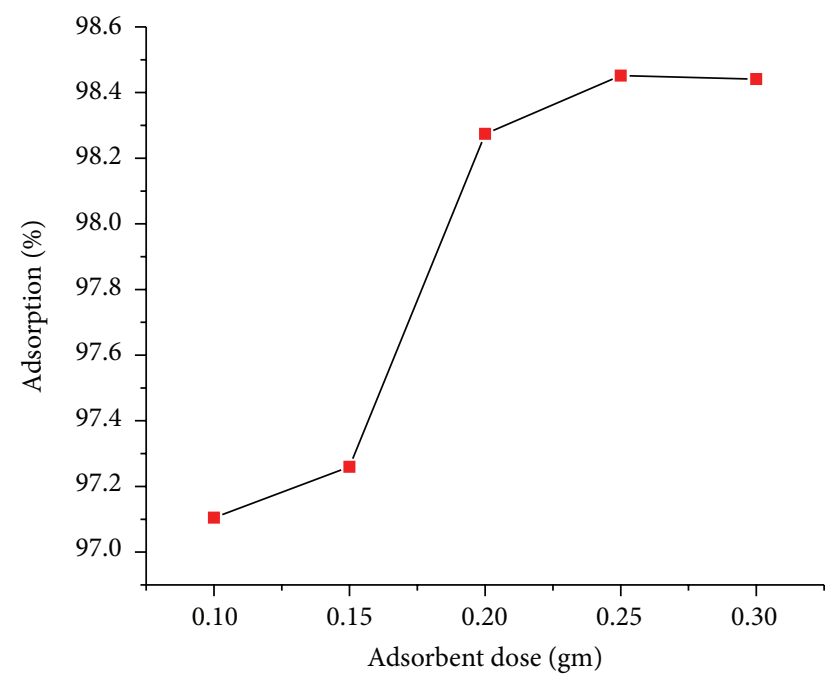

Figure 4: Effect of adsorbent dosage for adsorption of Hexavalent Chromium.

at a slower rate and finally attain saturation. The initial fast reaction may be due to the increased number of vacant sites available at the initial stage; as a result there exists increased concentration gradient between adsorbate in solution and adsorbate in the adsorbent. Generally, by the time adsorption involves a surface reaction process, the initial adsorption is fast. Then, a slower adsorption would follow as the available adsorption site which is gradually decreased. This is due to the fact that a large number of vacant surface sites are available for adsorption during the initial stage, and after a lapse of time the remaining vacant surface sites are difficult to be occupied due to repulsive forces between the solute molecules on the solid and bulk phases [44]. Maximum percentage of adsorption ( $98.019 \%$ in $100 \mathrm{mg} / \mathrm{L}$ of solution) occurs at $20 \mathrm{~min}$; after that the percentage adsorption remains uniform.

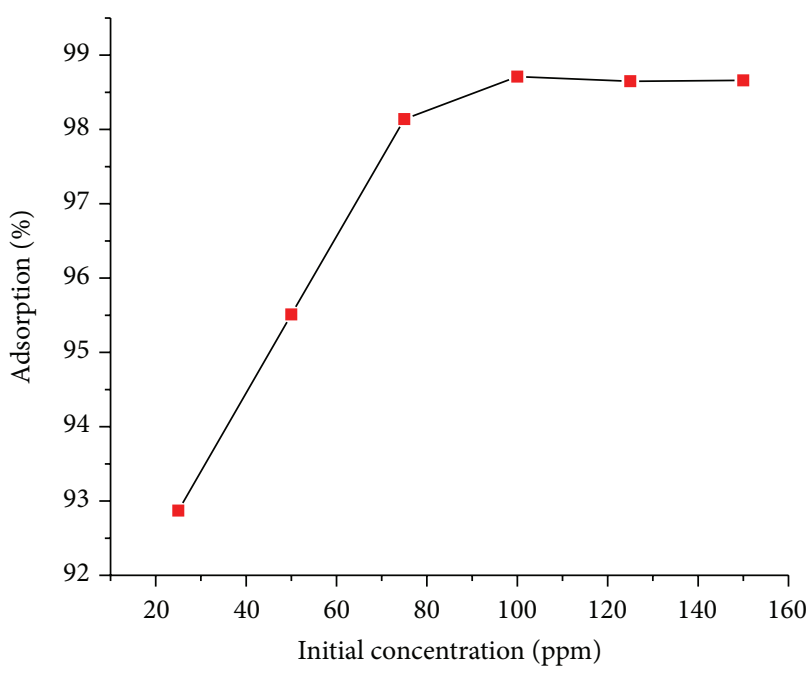

FIGURE 5: Effect of initial metal ion concentration for adsorption efficiency of Hexavalent Chromium.

3.4. Effect of Adsorbent Dosage. Figure 4 depicts effect of adsorbent dosage on the adsorption of chromium on the BWAC. It can be seen that the percent adsorption increases from 97.105 to $98.45 \%$ with an increase in the dose of BWAC from 0.1 to $0.25 \mathrm{~g}$ and remained nearly constant at adsorbent quantities higher than $0.25 \mathrm{~g}$. This is due to the greater availability of adsorption sites of adsorbent and thus making easier penetration of $\mathrm{Cr}(\mathrm{VI})$ to the adsorption sites [44]. Since the quantity of metal ion is constant, an increase in the amount of adsorbent above a quantity that can completely adsorb the available $\mathrm{Cr}(\mathrm{VI})$ had no apparent effect on further increase of percent adsorption. The adsorption capacity decreases from 24.28 to 8.2 for Hexavalent Chromium as dosage increased.

3.5. Effect of Initial Concentration on Adsorption. The effect of initial Hexavalent Chromium concentration on the adsorption efficiency of BWAC under optimum conditions of $\mathrm{pH}$ and contact time is shown in Figure 5. The adsorption efficiency increased from 92.87 to $98.71 \%$ for Hexavalent Chromium with increasing initial concentration from 25 to $150 \mathrm{mg} / \mathrm{L}$ but the solution reached equilibrium at $100 \mathrm{mg} / \mathrm{L}$ and after that no significant change occurred in adsorption.

The adsorption capacity increases from 9.87 to $59.23 \mathrm{mg} / \mathrm{g}$ for Hexavalent Chromium as the initial metal ion concentration increased from 25 to $150 \mathrm{mg} / \mathrm{L}$. This is because a higher initial concentration enhanced the driving force between the aqueous and solid phases and increased the number of collisions between metal ions and adsorbents [45]. However, the actual percentage adsorption of the metal ions from solution increased with the increase in the initial metal ion concentrations. This may be due to the fact that, at lower concentrations, adsorption of the metal ions occurred slowly and further increase in initial metal ion concentration led to a competition for available bonding sites on the BWAC surface by the metal ions and thus increased adsorption. Similar adsorption procedures have also been reported by other researchers [46]. The adsorption capacity of an adsorbent 


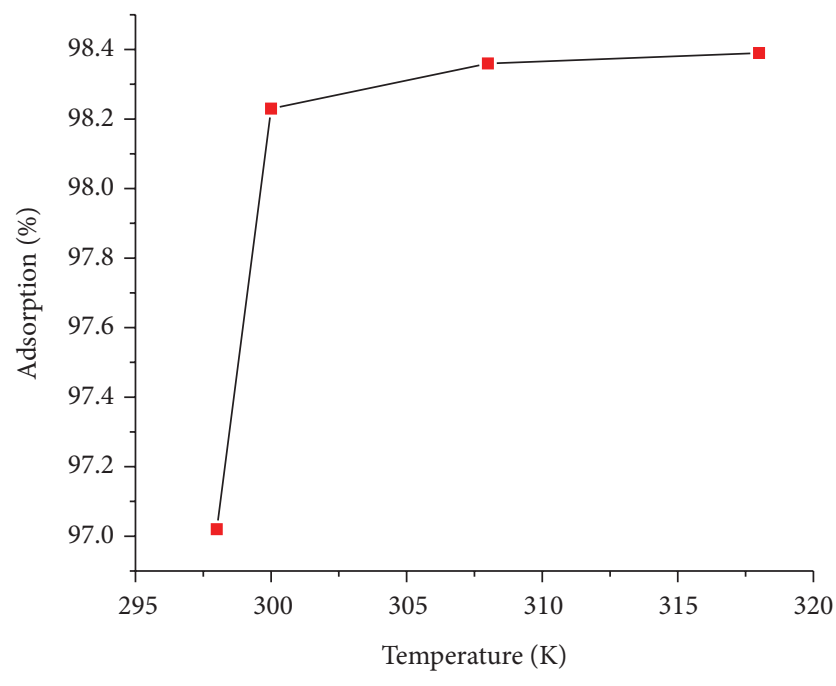

Figure 6: Effect of temperature for adsorption of Hexavalent Chromium.

which is obtained from the mass balance equation on the adsorbate in a system with solution volume is often used to acquire the experimental adsorption isotherms [47].

3.6. Effect of Temperature on Adsorption. Temperature is a highly significant parameter in the adsorption process. Experiments were performed at different temperatures $(298 \mathrm{~K}, 300 \mathrm{~K}, 308 \mathrm{~K}$, and $318 \mathrm{~K})$ at optimum $\mathrm{pH}$ and contact time. It was observed that the percentage of adsorption increases from 97.02 to 98.39 for Hexavalent Chromium ions with the rise in temperature from 298 to $318 \mathrm{~K}$. It is evident from Figure 6 that adsorption increases with the rising temperature because this adsorbent is not homogenous, and implying the active energy of adsorption sites is different. Therefore, at low temperature, the adsorption sites with lower active energy were occupied first, and the other sites with higher active energy were occupied as the temperature increases [29].

The rise of adsorption capacity with temperature was due to the increase in kinetic energy of adsorbent particles. Thus the collision frequency between adsorbent and adsorbate increases, which results in the enhanced adsorption onto the surface of the adsorbent. Secondly, at high temperature due to bond rupture of functional groups on adsorbent surface increases active adsorption sites, which may also lead to enhanced adsorption [48].

3.7. Adsorption Isotherms. Isotherm studies are essential to interpret the adsorption process adequately. Several models have been used to describe experimental data for adsorption isotherms. However, among these, the Langmuir and Freundlich isotherms are the most appropriate models for this study. According to the Langmuir isotherm, adsorption occurs at homogenous sites and forms a monolayer. In other words, once adsorbate is attached to a site, no further adsorption can take place [13]. The linear form of Langmuir isotherm equation is given as

$$
\frac{C_{e}}{q_{e}}=\frac{C_{e}}{q_{m}}+\frac{1}{q_{m} b_{L}},
$$

where $q_{e}(\mathrm{mg} / \mathrm{g})$ is the equilibrium concentration of Hexavalent Chromium in the adsorbed phase and $C_{e}(\mathrm{mg} / \mathrm{L})$ is the equilibrium concentration in the liquid phase. Langmuir constants, which are related to the adsorption capacity $\left(q_{m}\right)$ and energy of adsorption $\left(b_{L}\right)$, can be calculated from the slope of the linear plot of $C_{e} / q_{e}$ versus $C_{e}$; a straight line with slope $1 / q_{\max }$ and intercept of $1 / q_{\max } b_{L}$ is obtained. The essential characteristics of the Langmuir equation can be expressed in terms of a dimensionless factor, $R_{L}$ which is given as

$$
R_{L}=\frac{1}{1+b_{L} C_{0}},
$$

where $C_{0}$ is the highest initial Hexavalent Chromium ion concentration $(\mathrm{mg} / \mathrm{L})$. The values of separation factor $R_{L}$ have its usual significance.

Freundlich isotherm gives the relationship between equilibrium liquid and solid phase capacity based on the multilayer adsorption properties consisting of heterogeneous surface of the adsorbent. This isotherm is derived from the assumption that the adsorption sites are distributed exponentially with respect to the heat of adsorption [17]. The linear form of Freundlich isotherm is

$$
\log q_{e}=\log K_{f}+\frac{1}{n} \log C_{e},
$$

where $q_{e}$ is the amount adsorbed at equilibrium ( $\left.\mathrm{mg} / \mathrm{g}\right), K_{f}$ and $n$ are the Freundlich constant, $1 / n$ is the heterogeneity factor which is related to the capacity and intensity of the adsorption, and $C_{e}$ is the equilibrium concentration $\left(\mathrm{mgL}^{-1}\right)$. The values of $K_{f}$ and $1 / n$ can be obtained from the slope and intercept of the plot of $\log q_{e}$ against $\log C_{e}$. However, present investigation attempted to analyze the above-mentioned isotherm parameters at $300 \mathrm{~K}$ and the correlation coefficients $R^{2}$ were calculated by fitting the experimental equilibrium data for Hexavalent Chromium ion BWAC system using both Langmuir and Freundlich isotherms, which is presented in Table 2.

The results clearly show that the adsorption of Hexavalent Chromium on BWAC fits well with the Freundlich model. The fact that the Freundlich model is a good fit to the experimental adsorption data suggests physical adsorption as well as a heterogeneous distribution of active sites on the BWAC surface. The observed correlation coefficients for Freundlich isotherms were 0.775 . If the value of $n$ is equal to unity, the adsorption is linear. If the value of constant $n$ is below unity, it implies that the adsorption process is unfavorable, and if the value of $n$ is above unity, adsorption is favorable [33]. In the present study, the value of $n$ at equilibrium was above unity, suggesting favorable adsorption. Furthermore, the values of the dimensionless factor, $R_{L}$, were between 0 and 1 which suggest a favorable adsorption between BWAC and Hexavalent Chromium ion. 
TABLE 2: Results of isotherm models for the adsorption of Hexavalent Chromium by BWAC at $300 \mathrm{~K}$.

\begin{tabular}{lc}
\hline Adsorption isotherms constants & Values \\
\hline Langmuir isotherm & \\
$\quad q_{m}(\mathrm{mg} / \mathrm{g})$ & 125 \\
$b_{L}(\mathrm{~L} / \mathrm{mg})$ & 8.23 \\
$R^{2}$ & 0.018 \\
Freundlich isotherm & \\
$\quad K_{f}$ & 0.644 \\
$1 / n$ & 0.932 \\
$R^{2}$ & 0.775 \\
Separation factor, $R_{L}(\mathrm{mg} / \mathrm{L})$ & 0.012 \\
\hline
\end{tabular}

TABLE 3: Kinetics parameters for the adsorption of Hexavalent Chromium on BWAC at $300 \mathrm{~K}$.

\begin{tabular}{lc}
\hline Kinetic constants & Values \\
\hline Pseudo-first-order & \\
$q_{e}(\mathrm{exp}).(\mathrm{mg} / \mathrm{g})$ & 1.21 \\
$q_{e}(\mathrm{cal}).(\mathrm{mg} / \mathrm{g})$ & 1 \\
$k_{1} \times 10^{-4}\left(\mathrm{~min}^{-1}\right)$ & 1.16 \\
$R^{2}$ & 0.842 \\
Pseudo-second-order & \\
$\quad q_{e}(\mathrm{cal}).(\mathrm{mg} / \mathrm{g})$ & 1.2 \\
$k_{2}(\mathrm{mg} / \mathrm{g} / \mathrm{min})$ & 0.834 \\
$R^{2}$ & 0.997 \\
Intraparticle diffusion & \\
$k_{d}(\mathrm{mg} / \mathrm{g} / \mathrm{min})$ & 0.009 \\
$C$ (mg/g), intraparticle diffusion constant & 0.34 \\
$R^{2}$ & 0.908 \\
\hline
\end{tabular}

exp.: experimental result; cal.: calculated result.

3.8. Adsorption Kinetic Studies. In order to evaluate the kinetic parameters, pseudo-first-order and pseudo-secondorder models were implemented to analyze the experimental data. The pseudo-first-order equation can be expressed as [46]

$$
\log \left(q_{e}-q_{t}\right)=\log q_{e}-\frac{k_{1}}{2.303} t
$$

where $q_{e}$ and $q_{t}$ represent the amount of adsorbed $(\mathrm{mg} / \mathrm{g})$ at equilibrium and at any time $t$ and $k_{1}$ is the first-order rate constant $\left(\mathrm{min}^{-1}\right)$. From the plots of $\log \left(q_{e}-q_{t}\right)$ versus $t$ in Figure $7, k_{1}$ can be calculated from the slope and theoretical $q_{e}$ can be obtained from intercepts.

Pseudo-second-order equation can be given by

$$
\frac{t}{q_{t}}=\frac{1}{k_{2} q_{e}^{2}}+\frac{1}{q_{e}} t,
$$

where $k_{2}$ is the rate constant of second-order adsorption. The linear plots of $t / q_{t}$ versus $t$ determine $1 / q_{e}$ as slope and $1 / k_{2} q_{e}^{2}$ as intercepts. The linear plots of pseudo-second-order model are shown in Figure 7.

The correlation coefficient, $R^{2}$, of pseudo-first-order kinetics was 0.872 but the calculated $q_{e}(\mathrm{mg} / \mathrm{g})$ value obtained

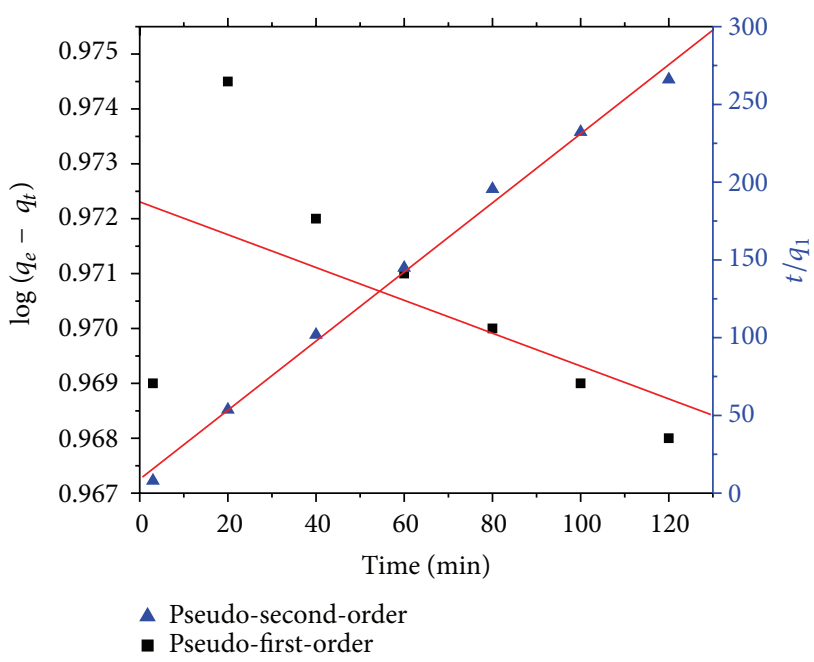

Figure 7: Kinetics plot for the adsorption of Hexavalent Chromium onto BWAC. (Blue triangle showing pseudo-second- and black squares is representing pseudo-first-order rate kinetics.)

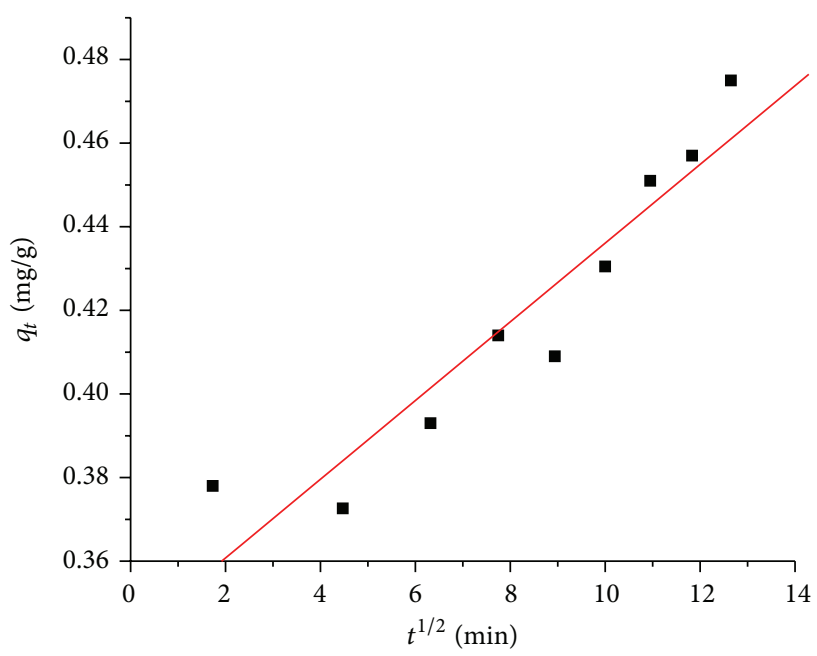

FIGURE 8: Intraparticle diffusion curve for adsorption of Hexavalent Chromium onto BWAC at $300 \mathrm{~K}$ temperature.

from pseudo-first-order kinetics did not agree well with the experimental (mg/g) values as shown in Table 3. Thus it can be concluded that it is not appropriate to use the pseudo-firstorder kinetic model to predict the adsorption kinetics for the adsorption of Hexavalent Chromium onto BWAC.

On the contrary, the correlation coefficient, $R^{2}$, for the second-order kinetic model was almost equal to unity for all the concentrations signifying the applicability of the model. Moreover, the calculated $q_{e}(\mathrm{mg} / \mathrm{g})$ values obtained from pseudo-second-order kinetics were in good agreement with the experimental $(\mathrm{mg} / \mathrm{g})$ values (Table 3$)$. Thus it appeared that the system under study is more suitably described by pseudo-second-order kinetics which was based on the assumption that the rate limiting step may be chemisorptions concerning valances forces through sharing and exchange of electrons. The pseudo-second-order kinetics model has been 
TABLE 4: Thermodynamic parameters for the adsorption of Hexavalent Chromium ion on BWAC at different temperatures.

\begin{tabular}{lcccc}
\hline$T(\mathrm{~K})$ & $\ln K_{c}$ & $\Delta G^{0}(\mathrm{~kJ} / \mathrm{mol})$ & $\Delta H^{0}(\mathrm{~kJ} / \mathrm{mol})$ & $\Delta S^{0}(\mathrm{~kJ} / \mathrm{mol} \cdot \mathrm{K})$ \\
\hline 298.2 & 3.340 & -8.28 & -18.912 & 0.06614 \\
308.2 & 3.7145 & -9.518 & & \\
318.2 & 7.3666 & -19.488 & & \\
\hline
\end{tabular}

TABLE 5: Comparison of adsorption capacity of different adsorbents for the adsorption of Hexavalent Chromium.

\begin{tabular}{lcc}
\hline Adsorbents & Adsorbent capacity $(\mathrm{mg} / \mathrm{g})$ & References \\
\hline Wood apple shell & 13.74 & {$[7]$} \\
Ricinus communis seed shell active carbon & 7.761 & {$[33]$} \\
Palm shell activated carbon & 12.6 & 20.5 \\
PEI/palm shell activated carbon & 10.93 & {$[34]$} \\
Acid-modified waste activated carbon & 35.7 & {$[35]$} \\
Fe-modified bamboo carbon & 59.23 & {$[36]$} \\
BWAC (bamboo waste activated carbon) & This work \\
\hline
\end{tabular}

successfully applied to several adsorption systems as reported in $[46]$.

The amount of Hexavalent Chromium adsorbed per unit mass of adsorbent at time $t, q_{t}$, as a function of the square root of the contact time, $t^{1 / 2}$ (Figure 8), was examined using the intraparticle diffusion model (Table 3 ) which is based on the theory proposed by Weber and Morris [49]:

$$
q_{t}=k_{d} t^{1 / 2}+C
$$

where $k_{d}(\mathrm{mg} / \mathrm{g} / \mathrm{min})$ is the intraparticle diffusion coefficient which was calculated from the slope of the linear portion of curves and $C(\mathrm{mg} / \mathrm{g})$ is intraparticle diffusion constant, that is, intercept of the line $(\mathrm{mg} / \mathrm{g})$. It is directly proportional to the boundary layer thickness. It is assumed that the larger the intercept, the greater the contribution of the surface adsorption in the rate-controlling step.

Intraparticle diffusion plays a significant role in controlling the kinetics of the adsorption process, if the plot of $q_{t}$ versus $t^{1 / 2}$ yields a straight line passing through the origin, with the slope giving the rate constant, $k_{d}$, and $C$. If the lines do not pass through the origin it is indicative of some degree of boundary layer control and this further shows that the intraparticle diffusion is not the only rate limiting step, but other kinetic models may also control the rate of adsorption $[34,50]$.

3.9. Thermodynamic Study. The thermodynamic parameters that help us to understand the nature of the adsorption of $\mathrm{Cr}(\mathrm{VI})$ ion on adsorbents are the standard change in Gibbs free energy $\left(\Delta G^{\circ}\right)$, the standard change in entropy $\left(\Delta S^{\circ}\right)$, and the standard change in enthalpy $\left(\Delta H^{\circ}\right)$. The enthalpy change $\left(\Delta H^{\circ}\right)$ from 298.2 to $318.2 \mathrm{~K}$ was computed from the following equation:

$$
\ln K_{c}=\frac{\Delta S^{\circ}}{R}-\frac{\Delta H^{\circ}}{R T},
$$

where $\Delta H^{\circ}\left(\mathrm{kJ} \cdot \mathrm{mol}^{-1}\right)$ and $\Delta S^{\circ}\left(\mathrm{kJ} \cdot \mathrm{mol}^{-1} \cdot \mathrm{K}^{-1}\right)$ were calculated from the slope and intercept of the linear plot of $\ln K_{c}$ versus $1 / T$. However, the calculated values of thermodynamic parameters are listed in Table 4 . The negative value of enthalpy change confirms the exothermic nature of the adsorption process. The enthalpy value for adsorption process may be used to distinguish between chemical and physical adsorption. For chemical adsorption, values of enthalpy change range from -83 to $-830 \mathrm{~kJ} / \mathrm{mol}$, while for physical adsorption they range from -8 to $-25 \mathrm{~kJ} / \mathrm{mol}$. The low values of $\Delta H$ give clear evidence that the interaction of Hexavalent Chromium and BWAC was weak suggesting physical adsorption process [50]. The positive value of entropy, $\Delta S^{\circ}$, represents an increase in the degree of freedom of the adsorbed species which indicates that some changes occur in the internal structure of BWAC during the adsorption process. The negative values of Gibbs free energy, $\Delta G^{\circ}$ demonstrate that the adsorption is rapid and spontaneous. The negative value of $\Delta G^{\circ}$ ensures the feasibility of the process. Generally, $\Delta G^{\circ}$ values range from 0 to $-20 \mathrm{KJ} / \mathrm{mol}$ for physical adsorption and -80 to $-400 \mathrm{KJ} / \mathrm{mol}$ for chemical adsorptions [34]. In this study, the $\Delta G^{\circ}$ values ranged from -6.347 to $-19.488 \mathrm{KJ} / \mathrm{mol}$, indicating that adsorption is mainly physical.

3.10. Comparison of Hexavalent Chromium Adsorption with Different Adsorbents. The adsorption capacity of the adsorbents for the adsorption of Hexavalent Chromium has been compared with those of others reported in the literature and the values of adsorption capacity as presented in Table 5. The experimental data of the present investigation were compared with reported values. Results of our investigation revealed that BWAC has the highest percent adsorption and adsorption capacity.

\section{Conclusion}

Experimental findings of this work suggested that the adsorption of Hexavalent Chromium on BWAC is a physical adsorption process attaining equilibrium within $20 \mathrm{~min}$. Both Freundlich and Langmuir models were used to fit the data 
to estimated model parameters but the overall data is better fitted by Freundlich isotherm. The kinetic studies conducted using the Weber and Morris equation showed that the adsorption mechanism involves intraparticle diffusion but it was not the fully operative mechanism in the adsorption of Hexavalent Chromium by BWAC. The pseudo-second-order kinetic model was found to be a better fit for the adsorption of Hexavalent Chromium by BWAC. Thermodynamic studies predict that the adsorption is feasible, spontaneous, and exothermic in nature at temperatures of 298.2, 308.2, and 318.2 K with negative values of standard change in Gibbs free energy $\left(\Delta G^{\circ}\right)$, enthalpy $\left(\Delta H^{\circ}\right)$, and positive values of standard entropy change $\left(\Delta S^{\circ}\right)$.

\section{Conflict of Interests}

The authors declare that there is no conflict of interests.

\section{Acknowledgment}

The authors thankfully acknowledge the Department of Chemistry, College of Natural Science, Jimma University, Ethiopia, for providing all necessary facilities required to carry out this work.

\section{References}

[1] V. K. Gupta, A. Rastogi, and A. Nayak, "Adsorption studies on the removal of hexavalent chromium from aqueous solution using a low cost fertilizer industry waste material," Journal of Colloid and Interface Science, vol. 342, no. 1, pp. 135-141, 2010.

[2] W.-Q. Wang, M.-Y. Li, and Q.-X. Zeng, "Thermodynamics of $\mathrm{Cr}(\mathrm{VI})$ adsorption on strong alkaline anion exchange fiber," Transactions of Nonferrous Metals Society of China, vol. 22, no. 11, pp. 2831-2839, 2012.

[3] R. Dobrowolski and M. Otto, "Study of chromium(VI) adsorption onto modified activated carbons with respect to analytical application," Adsorption, vol. 16, no. 4-5, pp. 279-286, 2010.

[4] J. O. Nriagu and E. Nieboer, "Chromium," in Natural and Human Environment, Wiley, New York, NY, USA, 1988.

[5] A. Mansri, K. I. Benabadji, J. Desbrières, and J. François, "Chromium removal using modified poly(4-vinylpyridinium) bentonite salts," Desalination, vol. 245, no. 1-3, pp. 95-107, 2009.

[6] E. Demirbas, M. Kobya, E. Senturk, and T. Ozkan, "Adsorption kinetics for the removal of chromium (VI) from aqueous solutions on the activated carbons prepared from agricultural wastes," Water SA, vol. 30, no. 4, pp. 533-540, 2004.

[7] A. S. Sartape, P. D. Raut, and S. S. Kolekar, "Efficient adsorption of chromium(VI) ions from aqueous solution onto a low-cost adsorbent developed from limonia acidissima (wood apple) shell," Adsorption Science and Technology, vol. 28, no. 6, pp. 547560, 2010

[8] R. A. Shawabkeh, "Adsorption of chromium ions from aqueous solution by using activated carbo-aluminosilicate material from oil shale," Journal of Colloid and Interface Science, vol. 299, no. 2, pp. 530-536, 2006.

[9] L. Monser and N. Adhoum, "Modified activated carbon for the removal of copper, zinc, chromium and cyanide from wastewater," Separation and Purification Technology, vol. 26, no. 2-3, pp. 137-146, 2002.
[10] Y. Jiang, Y. Wu, J. Liu, X. Xia, and D. Wang, "Ammonium pyrrolidinedithiocarbamate-modified activated carbon microcolumn extraction for the determination of As(III) in water by graphite furnace atomic absorption spectrometry," Microchimica Acta, vol. 161, no. 1-2, pp. 137-142, 2008.

[11] L. Khezami and R. Capart, "Removal of chromium(VI) from aqueous solution by activated carbons: kinetic and equilibrium studies," Journal of Hazardous Materials, vol. 123, no. 1-3, pp. 223-231, 2005.

[12] J. Gañan, C. González-García, J. González, E. Sabio, A. MacíasGarcía, and M. Díaz-Díez, "Preparation of activated carbons from bituminous coal pitches," Applied Surface Science, vol. 238, no. 1-4, pp. 347-354, 2004.

[13] M. Sekar, V. Sakthi, and S. Rengaraj, "Kinetics and equilibrium adsorption study of lead(II) onto activated carbon prepared from coconut shell," Journal of Colloid and Interface Science, vol. 279, no. 2, pp. 307-313, 2004.

[14] S. Babel and T. A. Kurniawan, "Cr(VI) removal from synthetic wastewater using coconut shell charcoal and commercial activated carbon modified with oxidizing agents and/or chitosan," Chemosphere, vol. 54, no. 7, pp. 951-967, 2004.

[15] R. A. Shawabkeh, D. A. Rockstraw, and R. K. Bhada, "Copper and strontium adsorption by a novel carbon material manufactured from pecan shells," Carbon, vol. 40, no. 5, pp. 781-786, 2002.

[16] M. Kobya, E. Demirbas, E. Senturk, and M. Ince, "Adsorption of heavy metal ions from aqueous solutions by activated carbon prepared from apricot stone," Bioresource Technology, vol. 96, no. 13, pp. 1518-1521, 2005.

[17] C. J. Durán-Valle, M. Gómez-Corzo, J. Pastor-Villegas, and V. Gómez-Serrano, "Study of cherry stones as raw material in preparation of carbonaceous adsorbents," Journal of Analytical and Applied Pyrolysis, vol. 73, no. 1, pp. 59-67, 2005.

[18] S. Yenisoy-Karakaş, A. Aygün, M. Güneş, and E. Tahtasakal, "Physical and chemical characteristics of polymer-based spherical activated carbon and its ability to adsorb organics," Carbon, vol. 42, no. 3, pp. 477-484, 2004.

[19] S. P. Dubey and K. Gopal, "Adsorption of chromium(VI) on low cost adsorbents derived from agricultural waste material: a comparative study," Journal of Hazardous Materials, vol. 145, no. 3, pp. 465-470, 2007.

[20] X. J. Wang, Y. Wang, X. Wang et al., "Microwave-assisted preparation of bamboo charcoal-based iron-containing adsorbents for Cr(VI) removal," Chemical Engineering Journal, vol. 174, no. 1, pp. 326-332, 2011.

[21] B. V. Babu and S. Gupta, "Adsorption of Cr(VI) using activated neem leaves: kinetic studies," Adsorption, vol. 14, no. 1, pp. 8592, 2008.

[22] S. S. Baral, S. N. Das, and P. Rath, "Hexavalent chromium removal from aqueous solution by adsorption on treated sawdust," Biochemical Engineering Journal, vol. 31, no. 3, pp. 216222, 2006.

[23] M. Nameni, M. R. Alavi Moghadam, and M. Arami, "Adsorption of hexavalent chromium from aqueous solutions by wheat bran," International Journal of Environmental Science and Technology, vol. 5, no. 2, pp. 161-168, 2008.

[24] E. A. Oliveira, S. F. Montanher, A. D. Andrade, J. A. Nóbrega, and M. C. Rollemberg, "Equilibrium studies for the sorption of chromium and nickel from aqueous solutions using raw rice bran," Process Biochemistry, vol. 40, no. 11, pp. 3485-3490, 2005.

[25] N. Vennilamani, K. Kadirvelu, Y. Sameena, and S. Pattabhi, "Utilization of activated carbon prepared from industrial solid 
waste for the removal of chromium(VI) ions from synthetic solution and industrial effluent," Adsorption Science and Technology, vol. 23, no. 2, pp. 145-160, 2005.

[26] G. H. Pino, L. M. S. De Mesquita, M. L. Torem, and G. A. S. Pinto, "Biosorption of heavy metals by powder of green coconut shell," Separation Science and Technology, vol. 41, no. 14, pp. 3141-3153, 2006.

[27] M. Kobya, E. Demirbas, and M. Bayramoglu, "Modelling the effects of adsorbent dose and particle size on the adsorption of $\mathrm{Cr}(\mathrm{VI})$ ions from aqueous solutions," Adsorption Science and Technology, vol. 22, no. 7, pp. 583-594, 2004.

[28] A. A. Attia, S. A. Khedr, and S. A. Elkholy, "Adsorption of chromium ion (VI) by acid activated carbon," Brazilian Journal of Chemical Engineering, vol. 27, no. 1, pp. 183-193, 2010.

[29] K. B. Nagashanmugama and K. Srinivasanb, "Removal of chromium (VI) from aqueous solution by chemically modified gingelly oil cake carbon," Indian Journal of Chemical Technology, vol. 18, no. 3, pp. 207-219, 2011.

[30] L. C. Romero, A. Bonomo, and E. E. Gonzo, "Peanut shell activated carbon: adsorption capacities for copper(II), zinc(II), nickel(II) and chromium(VI) ions from aqueous solutions," Adsorption Science and Technology, vol. 22, no. 3, pp. 237-243, 2004.

[31] Z. A. ALOthman, M. Naushad, and R. Ali, "Kinetic, equilibrium isotherm and thermodynamic studies of $\mathrm{Cr}(\mathrm{VI})$ adsorption onto low-cost adsorbent developed from peanut shell activated with phosphoric acid," Environmental Science and Pollution Research, vol. 20, no. 5, pp. 3351-3365, 2013.

[32] S. Hirunpraditkoon, N. Tunthong, A. Ruangchai, and K. Nuithitikul, "Adsorption cpacities of activated carbons prepared from bamboo by $\mathrm{KOH}$ activation," World Academy of Science, Engineering and Technology, vol. 54, pp. 647-651, 2011.

[33] P. Thamilarasu and K. Karunakaran, "Kinetic, equilibrium and thermodynamic studies on removal of $\mathrm{Cr}(\mathrm{VI})$ by activated carbon prepared from Ricinus communis seed shell," Canadian Journal of Chemical Engineering, vol. 91, no. 1, pp. 9-18, 2013.

[34] B. K. Hamad, A. M. Noor, and A. A. Rahim, "Removal of 4chloro-2-methoxyphenol from aqueous solution by adsorption to oil palm shell activated carbon activated with $\mathrm{K}_{2} \mathrm{CO}_{3}$," Journal of Physical Science, vol. 22, no. 1, pp. 39-55, 2011.

[35] M. Owlad, M. K. Aroua, and W. M. A. Wan Daud, "Hexavalent chromium adsorption on impregnated palm shell activated carbon with polyethyleneimine," Bioresource Technology, vol. 101, no. 14, pp. 5098-5103, 2010.

[36] P. K. Ghosh, "Hexavalent chromium [Cr(VI)] removal by acid modified waste activated carbons," Journal of Hazardous Materials, vol. 171, no. 1-3, pp. 116-122, 2009.

[37] W. Wang, X. Wang, X. Wang et al., “Cr(VI) removal from aqueous solution with bamboo charcoal chemically modified by iron and cobalt with the assistance of microwave," Journal of Environmental Sciences, vol. 25, no. 9, pp. 1726-1735, 2013.

[38] Annual Book of ASTM Standards, Standard Test Method for Moisture in Activated Carbon D2867-95.15.01. United State of America, 2004

[39] Annual Book of ASTM Standards, Standard Test Method for Total Ash Content of Activated Carbon. D2866-94. 15.01. United State of America, 1999.

[40] Annual Book of ASTM Standards, Standard Test Method for Volatile Matter Content of Activated Carbon Samples D583295. 15.01. United State of America, 2003.
[41] V. K. Garg, R. Gupta, R. Kumar, and R. K. Gupta, "Adsorption of chromium from aqueous solution on treated sawdust," Bioresource Technology, vol. 92, no. 1, pp. 79-81, 2004.

[42] K. Selvi, S. Pattabhi, and K. Kadirvelu, "Removal of Cr(VI) from aqueous solution by adsorption onto activated carbon," Bioresource Technology, vol. 80, no. 1, pp. 87-89, 2001.

[43] S. Muhammad, A. B. Alaadin, and N. A. Muhammad, "Electrocoagulation for the treatment of Wastewater for reuse in irrigation and plantation (Report)," Journal of Basic \& Applied Sciences, vol. 7, no. 1, pp. 11-20, 2011.

[44] D. Mohan, K. P. Singh, and V. K. Singh, "Trivalent chromium removal from wastewater using low cost activated carbon derived from agricultural waste material and activated carbon fabric cloth," Journal of Hazardous Materials, vol. 135, no. 1-3, pp. 280-295, 2006.

[45] S. Li, X. Lu, X. Li et al., "Preparation of bamboo-like PPy nanotubes and their application for removal of $\mathrm{Cr}(\mathrm{VI})$ ions in aqueous solution," Journal of Colloid and Interface Science, vol. 378, no. 1, pp. 30-35, 2012.

[46] N. Tewari, P. Vasudevan, and B. K. Guha, "Study on biosorption of Cr(VI) by Mucor hiemalis," Biochemical Engineering Journal, vol. 23, no. 2, pp. 185-192, 2005.

[47] X. L. Jiang and Y. H. Jiang, "Evaluation of the adsorption of $\mathrm{Cr}(\mathrm{VI})$ by modified bamboo shells," Applied Mechanics and Materials, vol. 361-363, pp. 709-715, 2013.

[48] Z. Hu, L. Lei, Y. Li, and Y. Ni, "Chromium adsorption on high-performance activated carbons from aqueous solution," Separation and Purification Technology, vol. 31, no. 1, pp. 13-18, 2003.

[49] J. W. Weber and J. C. Morris, "Kinetics of adsorption on carbon from solution," Journal of the Sanitary Engineering Division, vol. 89, no. 2, pp. 31-60, 1963.

[50] P. N. Dave, N. Pandey, and H. Thomas, "Adsorption of Cr(VI) from aqueous solutions on tea waste and coconut husk," Indian Journal of Chemical Technology, vol. 19, no. 2, pp. 111-117, 2012. 

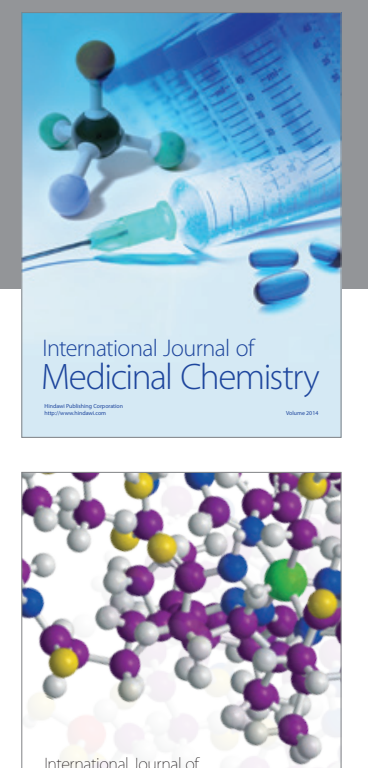

\section{Carbohydrate} Chemistry

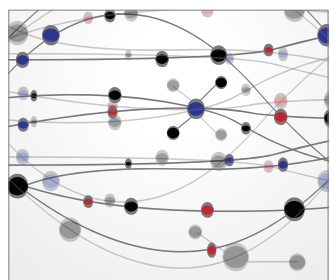

The Scientific World Journal
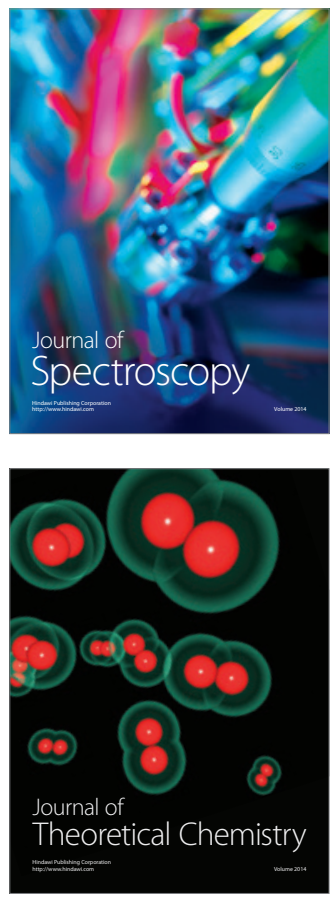
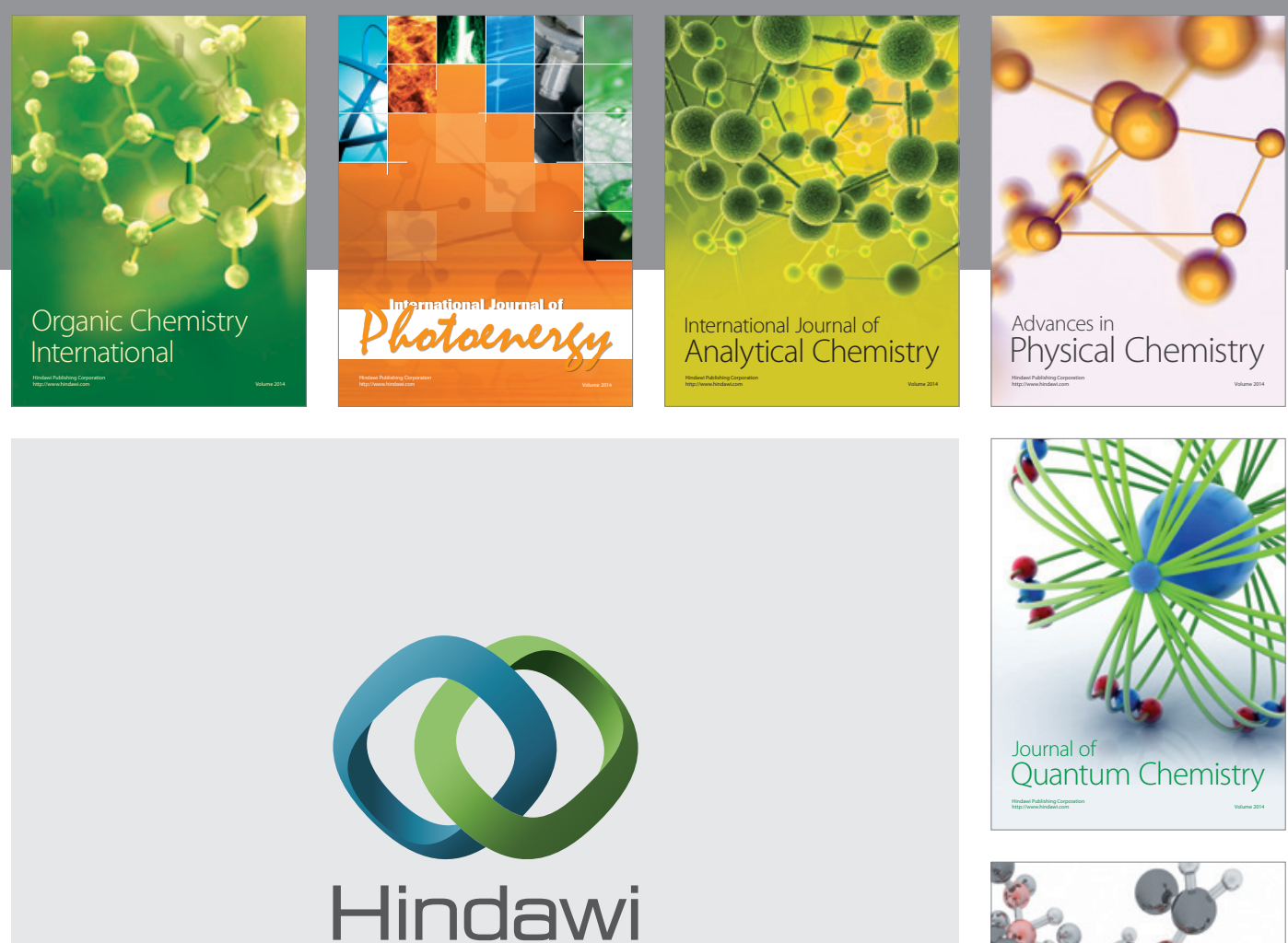

Submit your manuscripts at

http://www.hindawi.com

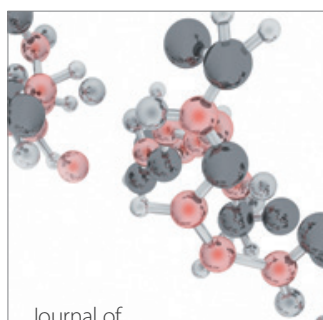

Analytical Methods

in Chemistry

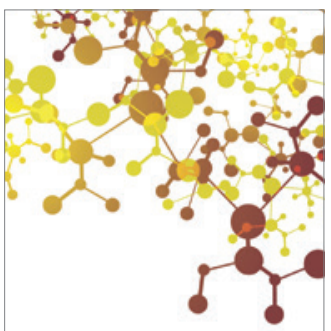

Journal of

Applied Chemistry

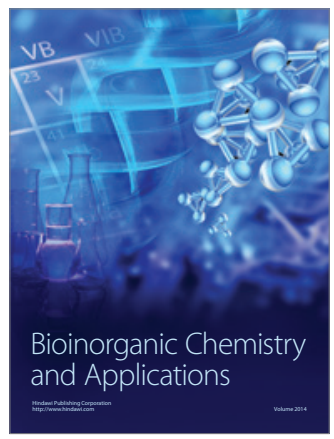

Inorganic Chemistry
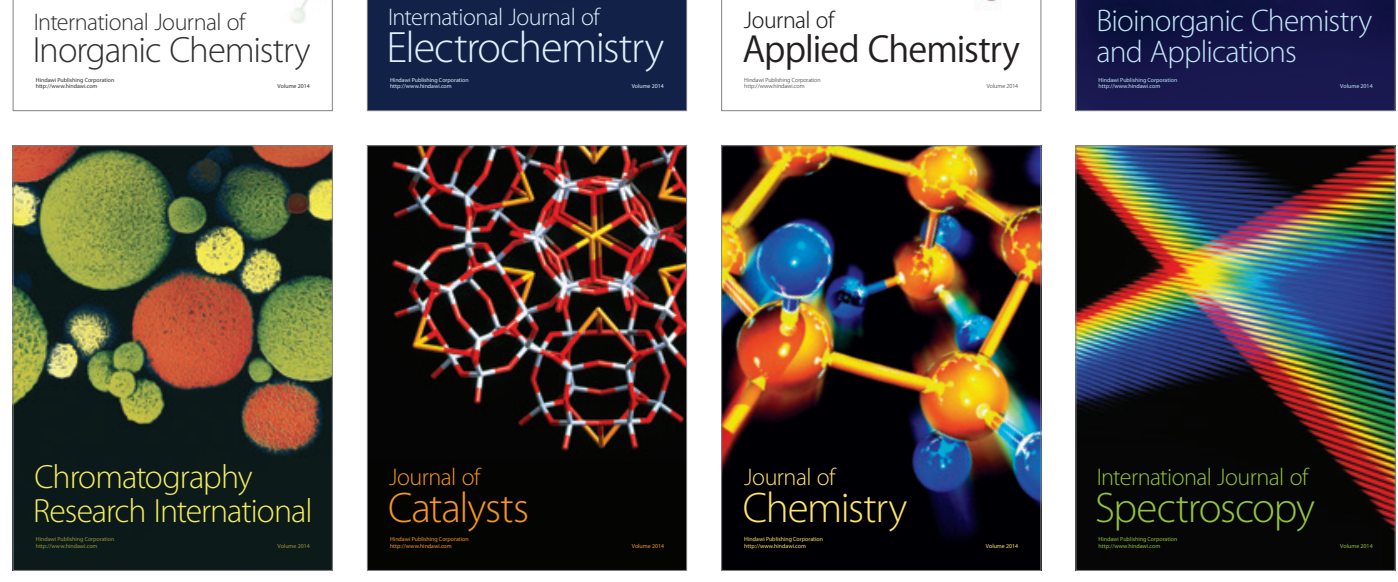